\title{
Contraindications, Risks, Complications in Interventional Pneumology
}

\author{
N. Facciolongo
}

Monaldi Arch Chest Dis 2011; 75: 1, 54-59.

Keywords: Bronchoscopy, Complication, Haemorrahage, Pneumothorax, Transbronchial needle aspiration.

Dipartimento Cardiotoracico, Struttura Complessa di Pneumologia, Ospedale Santa Maria Nuova, Reggio Emilia, Italy.

Correspondence: Dr. Nicola Facciolongo, Dipartimento Cardiotoracico, Struttura Complessa di Pneumologia, Ospedale Santa Maria Nuova, Via Risorgimento 80, 42100 Reggio Emilia, Italy; e-mail: Facciolongo.Nicola@asmn.re.it

Risk assessment and relative contraindications when performing a bronchoscopy are fundamental when carrying out a safe endoscopic test and preventing possible complications. There are many studies that have been carried out which support this statement. Yet, there have been no controlled trials establishing certain rules on the matter, solely consolidated habits based on experience and guidelines [1, 2] which are uniformly followed. In this article the risk factors concerning the patients are associated with endoscopic procedures so as to identify the progressive risk classes and assess the various relevant aspects.

\section{Inspection bronchoscopy}

$\underline{\text { Absolute contraindications }}$

\section{- None.}

Very high-risk conditions

- Serious heart arrhythmia (sinus bradycardia $<40$ bpm.

- Atrial fibrillation with ventricular response $>120 \mathrm{bpm}$.

- Supraventricular tachycardia $>140 / \mathrm{min}$.

- bpm; ventricular extrasystole $>50$ per hour.

- Severe refractory hypoxemia.

- Unstable ischemic heart disease (recent myocardial infarction <6 weeks; unstable angina; ongoing ischemia).

- Congestive cardiac failure.

- Ongoing bronchospasm.

High-risk conditions

- Unstable bronchial asthma.

- Superior caval syndrome.

- Cerebral metastasis.

- Chronic obstructive respiratory disease with $\mathrm{FEV}_{1}<1 \mathrm{~L}$.

- Hypercapnic respiratory failure.

- Myocardial infarction in a previous period ranging from 6 months to 6 weeks.

(Level of evidence: III).
During bronchoscopy, hypoxemia is a common occurrence. It can be caused by an alteration of the ventilation-perfusion ratio, hypoventilation related to sedation, increase of resistance due to the introduction of the bronchoscope, to incongruous aspiration manoeuvres by the operator [3]. The patient should always receive an oxygen supplement in order to maintain haemoglobin oxygen saturation of at least 92-94\%. Depending on the conditions, oxygen supplement and monitoring must continue for an additional 1-2 hours after the endoscopic procedure [4].

The monitoring of vital parameters with the pulse oxymetry should therefore be performed on all patients undergoing bronchoscopy [5-6] (Level of evidence: III).

There is no difference between the nasal or oral administration of $\mathrm{O}_{2}$ [7] (Level of evidence: $I b)$

If it is necessary to perform a bronchoscopy in very hypoxemic non-intubated patients, the procedure must be conducted in non-invasive mechanical ventilation with a facial mask or helmet. The published works show how this method entails a clear increase in oxygenation during the procedure as against the traditional Venturi mask ventilation $[8,10]$ (Level of evidence: $I b$ ).

Cardiac rhythm disorders were reported during bronchoscopy $[1,2]$. The moment when the risk of arrhythmia is higher is the passage through the vocal cords or the association with hypoxemia [11]. Many authors agree that it is necessary to maintain electrocardiographic monitoring during endoscopy in patients affected by heart rhythm alterations or known hypoxemia or in patients with severe cardiovascular disorders or unstable angina [12]. For the other patients, routine heart monitoring is not necessary [13] (Level of evidence: IV). 


\section{Recommendations}

- During bronchoscophy, the patient must always be monitored with pulse oxymetry, have a venous access and an oxygen supplement such as to keep $\mathrm{O}_{2}$ Saturation at $95 \%$ also up to 2 hours after the test (Grade B).

- In the case of patients with respiratory failure and serious hypoxemia, the test should be performed with noninvasive mechanical ventilation using a facial mask or a helmet (Grade A).

\section{Special conditions}

Patients under treatment with oral anticoagulants must suspend the medicament at least 3 days before the endoscopic procedure [14]. This statement is controversial because the current literature is substantially limited in its ability to help choose an optimal strategy [15] (Level of evidence: III).

The reaction of patients being treated with platelet anti-aggregates is controversial. Ticlopidine has a rapid action power and is active 1-2 hours after its administration and is eliminated after 24-96 hours. Clopidogrel has its maximum anti-aggregating power 4-7 days after administration [16]. It is therefore cautious to advise the suspension of ticlopidine 3-4 days and clopidogrel 6-7 days before the endoscopic procedure [17]. For patients undergoing treatment with Acetylsalicylic Acid the withdrawal of this drug for 48 hours before the endoscopic test is advisable [18] (Level of evidence: III).

In patients with prosthetic heart valves or who had rheumatic valve disorders and/or previous endocarditis, antibiotic prophylaxis can be of some use. In particular, it is not always necessary in cases of inspection bronchoscopy while it is actually advised if bioptic samples are taken [19] (Level of evidence: III).

\section{Recommendation}

- The patients under treatment with oral anticoagulants must suspend the therapy at least 72 hours before the test while those under treatment with Clopidogrel at least 6-7 days before (Grade C).

\section{Bronchial asthma}

Occasional cases of bronchospastic reactions from moderate to severe, due to bronchoscopy, have been reported in literature [20].

The predictive factors used to identify asthmatic patients with high bronchospasm risk during the procedure are: high bronchial hyperactivity, basal $\mathrm{FEV}_{1}<60 \%$ than the theoretical value, unstable asthma with frequent bronchial crises and relevant symptoms, patients who suffer from asth- ma or who had previously undergone treatment in an Intensive Care Unit owing to bronchospastic crises [21] (Level of evidence: IV).

\section{COPD}

Patients affected by severe COPD with $\mathrm{FEV}_{1} /$ $\mathrm{FVC}<50 \%$ or $\mathrm{FEV}_{1}<1.2 \mathrm{~L}$ are more likely to encounter complications than those with normal functional values [22]. In cases of hypoxemia and/ or hypercapnia, attention must be paid to oxygen supplementation during the procedure and/ or possible sedation which could induce or worsen the latent hypercapnia [23] (Level of evidence: IV).

\section{Ischemic heart disease}

A bronchoscopy can induce myocardial ischemia in elderly patients or patients with known ischemic heart disease [24]. The bronchoscopy should not be performed during acute ischemia or, for at least 12 days following an acute myocardial infarction. If absolutely necessary, the bronchoscopy must be performed with continuous electrocardiographic, pulse oxymetry monitoring and oxygen supplement. The risk of complications during bronchoscopy is very low after 4-6 weeks from the acute ischemic event $[25,26]$ (Level of evidence: III).

\section{Recommendations}

- Patients affected by unstable asthma or with known severe COPD must undergo complete spirometry, blood gas analysis and pre-medication with aerosol bronchodilators (Grade C).

- In patients with recent acute myocardial infarction, bronchoscopy must be performed after 4-6 weeks from the acute event (Grade $B$ ).

\section{Bronchial biopsies (BB) of central bronchopulmonary lesions}

Absolute contraindications

- None.

Very high-risk conditions and high-risk conditions

- The same as inspection bronchoscopy.

- Severe coagulopathy (platelets $<50,000 /$ microliter; PT $>30 \mathrm{sec}$ ).

(Level of evidence: III).

\section{Transbronchial lung biopsy (TBLB)}

\section{Absolute contraindications}

- Severe coagulopathy (platelets $<30,000 /$ microliter and/or PT $>30 \mathrm{sec}$ ).

- The same as inspection bronchoscopy.

Very high-risk conditions

- The same as inspection bronchoscopy. 
High-risk conditions

- Anatomic or functional pneumonectomy.

- Pulmonary hypertension.

- Uraemia (creatininemia $>3 \mathrm{mg} / \mathrm{dl}$ ).

- Platelet count between 30,000 and 50,000/microliter.

- Mechanically ventilated patient.

(Level of evidence: III).

The risk of bleeding is high for BB in patients with platelet values $<$ of 50,000/microliter and for the TBLB for the values of platelets between 30,000 and $50,000 /$ microliter. For platelets values inferior to $30,000 /$ microliter TBLB is contraindicated [27] (Level of evidence: IV).

\section{Recommendation}

- Patients who are undergoing a TBLB must always be subjected to a blood chemistry analysis and coagulative profile test (Grade C).

\section{Special conditions}

\section{Uremic patients}

Uraemia causes alterations in platelet functionality with anomalies in the adhesion function to the vessel wall [28]. This leads to an increase of bleeding time and higher risk of haemorrhage complications in invasive procedures. The risk of haemorrhage complications in bronchoscopy is around 3 times higher than in non-uremic patients [29] (Level of evidence: IV).

\section{Patients in mechanical ventilation}

The published works show a higher incidence of complications, such as haemorrhage and pneumothorax, especially for TBLB as against those not ventilated, even though no increase in the mortality rate is reported. If the endoscopic risk is connected with the percentages of correctly conducted diagnoses, which range from 33 to $76 \%$ with consequent therapeutic strategy change, it can be said that the risk-benefit ratio of the endoscopic procedure in terms of therapeutic response is surely in favour of the latter and, thus, recommended [30] (Level of evidence: $I V$ ).

\section{Immunocompromised patients}

Immunocompromised patients undergoing FBS are at higher risk of complications than immunocompetent patients [31]. The risk of bleeding in transplanted patients is higher than normal, but it seems to be unrelated to coagulation parameters, platelet count and / or immunodepressive and antiaggregating theraphy [32] (Level of evidence: III).

\section{Bronchoalveolar lavage (BAL)}

Absolute contraindications

- Clinically evident left ventricular insufficiency.

Very high-risk conditions

- The same as inspection bronchoscopy.

- Thrombocytopenia with platelets $<10,000 / \mathrm{mi}-$ croliter.

- Mechanically ventilated patient with $\mathrm{PaO}_{2}<70$ mmhg.

- With $\mathrm{FiO}_{2}>70 \%$ and a PEEP $\geq 15 \mathrm{~cm} \mathrm{H}_{2} \mathrm{O}$ and/or ongoing bronchospasm.

High-risk conditions

- The same as inspection bronchoscopy.

(Level of evidence: III).

\section{Mechanically ventilated patients}

Mechanically ventilated patients undergoing BAL present a reduction of the $\mathrm{PaO}_{2} / \mathrm{FiO}_{2}$ ratio with persistent hypoxemia which continues also after the procedure itself. It is advisable to perform these manoeuvres by increasing the $\mathrm{FiO}_{2}$ up to $100 \%$ during and after the procedure until normalization of oxygenation [33] (Level of evidence: III).

Transbronchial needle aspiration (TBNA)

$\underline{\text { Absolute contraindications }}$

- None.

High-risk conditions

- The same as inspection bronchoscopy.

Very high-risk conditions

- The same as inspection bronchoscopy.

(Level of evidence: III).

\section{Complications}

Complications mean any adverse event occurred to the patients before, during or immediately after the endoscopic procedure and which is no doubt related and consequent to the procedure itself. Creedle [34] reported a mortality rate of $0.1 \%$ and an incidence of complications higher than $0.8 \%$, while Suratt [35] a mortality rate of $0.03 \%$ and complication rate higher than $0.3 \%$. A recent prospective study on 20986 bronchoscopy show complications rate of $1.08 \%$ and mortality rate of $0.02 \%$ [36].

\section{Complications in flexible endoscopy}

During the pre-treatment and anaesthetic phase allergic, neurologic, cardiovascular and respiratory complications - partially related to the dose of medication used for anaesthesia or sedation - have been reported [37]. In fact there is no standardisation of the type of anaesthesia and sedation that should be be used when performing a FBS [38]. A recent publication showed that the daily application of guidelines in thoracic endoscopy can lead to a reduction of complication incidence [39] (Level of evidence: III). 
Complications which could arise during or after the bronchoscopy are varied, yet their incidence is low and range between 0.5 and $2.7 \%$ depending on the case histories reported above, while the mortality rate is assessed below $0.5 \%$ [40]. The most frequently reported complications are haemorrhage, pneumothorax, hypoxemia and cardiovascular complications (major arrhythmia, acute pulmonary oedema, myocardial ischemia). Many authors agree that TBLB is the procedure with the highest incidence of complications, around 3 times higher than a normal $\mathrm{BB}$ and that this percentage tends to exponentially increase in patients affected by serious pre-existing disorders [36]. Special attention must be paid to patients with acute or chronic renal insufficiency, to patients with serious haematologic disorders, immmunodepressed or in mechanical ventilation patients [41] (Level of evidence: III).

Only in cases of nodule biopsy is it useful to perform TBLB with the fluoroscopic screening in order to prevent haemorrhagic or pneumothoracic complications. In cases of diffuse pulmonary disorders, the use of fluoroscopic screening does not reduce the incidence of pneumothorax or haemorrhages and is thus never considered essential [2]. Performing chest-X-rays after TBLB in asymptomatic patients did not prove to be useful in highlighting the development of pnuemothorax [42] (Level of evidence: IV).

\section{Recommendations}

- The patients undergoing TBLB must be kept under observation for at least 2 hours and undergo chest-X-ray for symptomatic patients or patients with persistent pain (Grade C).

- In cases of pneumothorax with a flap of less than $2 \mathrm{~cm}$ and in an asymptomatic patient, it is advisable to keep a conservative attitude or to perform flap aspiration. For pneumothorax > of $2 \mathrm{~cm}$ the positioning of thoracic drainage is advisable (Grade B).

\section{Complications in rigid endoscopy}

The frequency of complications in rigid bronchoscopies can be quantified approximately 3 times higher than that reported in diagnostic procedures with flexible bronchoscope to which the anaesthesiological risk must be added [36, 43, 44] (Level of evidence: III).

This is determined by the fact that patients undergoing these procedures require complex endoscopic manoeuvres often performed in urgency/ emergency and have been already excluded by other types of treatment. The main complications are haemorrhage, hypoxia often caused by the former and perforation.

\section{Recommendation}

- In cases of haemorrhage, it is necessary to hyper-oxygenate the patient, perform a lavage and repeated aspirations with cold saline aimed at keeping the air ways accessible must be performed, the patient must lie on the side hit by the haemorrhage to preserve the healthy side (Grade C).

\section{Conclusions}

Bronchoscopy, both with flexible and rigid instruments, is basically a secure procedure, well tolerated and with a low incidence rate of complications during the diagnostic and operational phases provided that it is performed in the best conditions possible. In order to do so the operators must be experts or trainees carefully followed by tutors when carrying out the most complex operations. It is necessary to always exhaustively and clearly inform the patients on the type of operations that will be performed and acquaint them with all possible complications, so that they are aware of them and can recognise them in case of late events

It is essential to have an adequate number of people in the medical-nursing team, composed of experts in cardio-pulmonary resuscitation and orotracheal intubation; to have monitoring systems for the vital parameters enabling to precociously highlight any complication. It is advisable to perform the most complex operations where a resuscitation service and Intensive Care Unit are available, if necessary, along with a possible thoracic surgery unit (Level of evidence: IV).

\section{Summary of Recommendations}

- During bronchoscophy, the patient must always be monitored with pulse oxymetry, have a venous access and an oxygen supplement such as to keep $\mathrm{O}_{2}$ Saturation at $95 \%$ also up to 2 hours after the test (Grade $B$ ).

- In the case of patients with respiratory failure and serious hypoxemia, the test should be performed with non-invasive mechanical ventilation using a facial mask or a helmet (Grade A).

- The patients under treatment with oral anticoagulants must suspend the therapy at least $\mathbf{7 2}$ hours prior to the test while those under treatment with Clopidogrel at least 6-7 days before (Grade C).

- Patients affected by unstable asthma or with known severe COPD must undergo complete spirometry, arterial blood gas analysis and pre-med- 
ication with aerosol bronchodilators (Grade C).

- In patients with recent acute myocardial infarction, a bronchoscopy must be performed after 4-6 weeks from the acute event (Grade B).

- Patients who are going to undergo a TBLB must always be subject to blood chemistry analysis and coagulative profile test (Grade C).

- The patients undergoing TBLB must be kept under observation for at least 2 hours and undergo chest-X-ray for symptomatic patients or patients with persistent pain (Grade $\mathrm{C}$ ).

- In cases of pneumothorax with flap inferior to $2 \mathrm{~cm}$ and asymptomatic patient, it is advisable to keep a conservative attitude or to perform flap aspiration. For pneumothorax $>$ of 2 $\mathrm{cm}$ the positioning of thorax drainage is advisable (Grade B).

- In case of haemorrhage, it is necessary to hyper-oxygenate the patient, perform a lavage and repeated aspirations with cold saline aimed at keeping the air ways accessible must be performed, the patient must lie on the side hit by the haemorrhage to preserve the healthy side (Grade C).

\section{References}

1. Casalini AG, Cavaliere S, Consigli GF, et al. Standard operativi e linee guida in endoscopia toracica. Rassegna di Patologia dell'Apparato Respiratorio 1997; 12: 293 355.

2. British Thoracic Society Bronchoscopy Guidelines Committee, a Subcommittee of Standards of Care Committee of British Thoracic Society. British Thoracic Society guidelines on diagnostic flexible bronchoscopy. Thorax 2001; 56 Suppl 1: i1-21.

3. Matsushima Y, Jones RL, King EG, et al. Alterations in pulmonary mechanics and gas exchange during routine fiberoptic bronchoscopy. Chest 1984; 86: 184-188.

4. Jones AM, O'Driscoll R. Do all patients require supplemental oxygen during flexible bronchoscopy? Chest 2001; 119: 1906-9.

5. Kristensen MS, Milman N, Jarnvig IL. Pulse oximetry at fiberoptic bronchoscopy in local anaesthesia: indication for postbronchoscopy oxygen supplementation? Respir Med 1998; 92: 432-7.

6. Milman N, Faurschou P, Grode G, et al. Pulse oximetry during fibreoptic bronchoscopy in local anaesthesia: frequency of hypoxemia and effect of oxygen supplementation. Respiration 1994; 61: 342-7.

7. McCain TW, Dunagan DP, Adair NE, et al. Prospective randomized trial comparing oxygen administration during nasal flexible bronchoscopy: oral vs nasal delivery. Chest 2001; 120: 1671-4.

8. Maitre B, Jaber S, Maggiore SM, et al. Continuous positive airway pressure during fibreoptic bronchoscopy in hypoxemic patients. A randomized double-blind study using a new device. Am J Respir Crit Care Med 2000; 162: 1063-7.
9. Antonelli M, Conti G, Rocco M, et al. Noninvasive positive-pressure ventilation vs. conventional oxygen supplementation in hypoxemic patients undergoing diagnostic bronchoscopy Chest 2002; 121: 1149-54.

10. Rocco M, Dell'Utri D, Morelli A, et al. Noninvasive ventilation by helmet or face mask in immunocompromised patients: a case-control study. Chest 2004; 126: 1508-15.

11. Katz AS, Michelson EL, Stawicki J, Holford FD. Cardiac arrhythmias. Frequency during fiberoptic bronchoscopy and correlation with hypoxemia. Arch Intern Med 1987; 141: 603-6.

12. Mator I, Kramer M, Glantz L, et al. Myocardial ischemia in sedated patient undergoing fiberoptic bronchoscopy. Chest 1997; 112: 1454-8.

13. Vasic N. The role of ECG monitoring during bronchoscopy in lung cancer patients. Support Care Cancer 1995; 3: 402-8.

14. Kearon C, Hirsh J. Management of anticoagulation before and after elective surgery. N Engl J Med 1997; 336: 1506-11.

15. Dunn AS, Turpie AG. Perioperative management of patients receiving oral anticoagulants: a systematic review. Arch Intern Med 2003; 163: 901-8.

16. Patrono C, Coller B, FitzGerald GA, et al. Platelet-active drugs: the relationships among dose, effectiveness, and side effects: the Seventh ACCP Conference on Antithrombotic and Thrombolytic Therapy. Chest 2004; 126(3 suppl): 234S-264S.

17. Ernst A, Eberhardt R, Wahidi M, et al. Effect of routine clopidogrel use on bleeding complications after TBLB in humans. Chest 2006; 129: 734-7.

18. Herth FJ, Becker HD, Ernst A. Aspirin does not increase bleeding complications after TBLB. Chest 2002; 122: 1461-4.

19. Wilson W, Taubert KA, Gewitz M, et al. Prevention of infective endocarditis: guidelines from the American Heart Association: a guideline from the American Heart Association Rheumatic Fever, Endocarditis and Kawasaki Disease Committee, Council on Cardiovascular Disease in the Young, and the Council on Clinical Cardiology, Council on Cardiovascular Surgery and Anesthesia, and the Quality of Care and Outcomes Research Interdisciplinary Working Group. J Am Dent Assoc 2008; 139 Suppl: 3S-24S.

20. Djukanovic R, Wilson JW, Lai CK, et al. The safety aspects of fiberoptic bronchoscopy, bronchoalveolar lavage, and endobronchial biopsies in asthma. Am Rev Respir Dis 1991; 143: 772-7.

21. Elston WJ, Whittaker AJ, Khan LN, et al. Safety of research bronchoscopy, biopsy and bronchoalveolar lavage in asthma. Eur Respir J 2004; 24: 375-7.

22. Peacock M, Jonson J, Blanton H. Complications of flexible bronchoscopy in patient with severe obstructive pulmonary disease. J Bronchol 1994; 1: 181-6.

23. Hattotuwa K, Gamble EA, O'Shaughnessy T, et al. Safety of bronchoscopy, biopsy, and BAL in research patients with COPD. Chest 2002; 122: 1909-12.

24. Davies L, Mistre R, Spence DP. Cardiovascular consequences of fiberoptic bronchoscopy. Eur Respir J 1997; 10: 695-8.

25. American College of Cardiology and American Heart Association Taskforce. Guideline for peri-operative cardiovascular evaluation for non cardiac surgery. Circulation 1996; 93: 1278-317.

26. Dweik R, Metha A, Meeker D, et al. Analysis of the safety of bronchoscopy after recent acute myocardial infarction. Chest 1996; 110: 825-8.

27. Wahidi MM, Rocha AT, Hollingsworth JW, et al. Contraindications and safety of transbronchial lung biopsy via flexible bronchoscopy. A survey of pulmonologists and review of the literature. Respiration 2005; 72: 285-95.

28. Gorge JN, Shattil SJ. The clincial importance of acquired abnormalities of platelet function. $N$ Engl J Med 1991; 324: 27-39. 
29. Stubbs SE, Brutinel WM: complications in Bronchoscopy (1995). In Bronchoscopy U.B.S. Prakash. Raven Press Mayo Fondation New Yoirk p 357-366.

30. Bulpa PA, Dive AM, Mertens L e al. Combined bronchoalveolar lavage and transbronchial lung biopsy: safety and yield in ventilated patients. Eur Respir J 2003; 21: 383-4.

31. Jain P, Sandur S, Meli Y, et al. Role of flexible bronchoscopy in immunocompromised patients with lung infiltrates. Chest 2004; 125: 712-22.

32. Diette GB, Wiener CM, White P Jr. The higher risk of bleeding in lung transplant recipients from bronchoscopy is independent of traditional bleeding risks: results of a prospective cohort study. Chest 1999; 115: 397-402.

33. Bauer TT, Torres A, Ewig S, et al. Effects of bronchoalveolar lavage volume on arterial oxygenation in mechanically ventilated patients with pneumonia. Intensive Care Med 2001; 27: 384-93.

34. Creedle W, Smiddy J, Elliott R. Complication of fiberoptic bronchoscopy. Am Rev Respir Dis 1974; 109: 67-72.

35. Suratt P, Smiddy J, Gruber B. Deaths and complication associated with fiberoptic bronchoscopy. Chest 1976; 69: 747-751.

36. Facciolongo N, Patelli M, Gasparini S, et al. Incidence of complications in bronchoscopy. Multicentre prospective study of 20,986 bronchoscopies. Monaldi Arch Chest Dis 2009; 71: 8-14.
37. Smyth CM, Stead RJ. Survey of flexible bronchoscopy in the United Kingdom. Eur Resipir J 2002; 19: 358463.

38. Pickles J, Jeffrey M, Datta A, et al. Is preparation for bronchoscopy optimal? Eur Respir J 2003; 22: 203-6.

39. Dransfield MT, Garver RI, Weill D. Standardized guidelines for surveillance bronchoscopy reduce complications in lung transplant recipients. J Heart Lung Transplant 2004; 23: 110-4

40. Colt H, Prakash UBS, Offord K. Bronchoscopy in North America. Survey by the American Association for Bronchology. J Bronchol 2000; 7: 8-25.

41. Mulabecirovic A, Gaulhofer P, Auner HW, et al. Pulmonary infiltrates in patients with haematologic malignancies: transbronchial lung biopsy increases the diagnostic yield with respect to neoplastic infiltrates and toxic pneumonitis. Ann Hematol 2004; 83: 420-2.

42. Izbicki G, Shitrit D, Yarmolovsky A, et al. Is routine chest radiography after TBLB necessary? A prospective study of 350 cases. Chest 2006; 129: 1561-4.

43. Lukomsky GI, Ovchinnikov AA, Bilal A. Complication of bronchoscopy: comparison of rigid bronchoscopy under general anestesia and flexible fiberoptic bronchoscopy under topical anesthesia. Chest 1981; 79: 316-21.

44. Cavaliere S, Venuta F, Foccoli P, Toninelli C, La Face B. Endoscopic treatement of malignant airway obstructions in 2,008 patients. Chest 1996; 110: 1536-42.

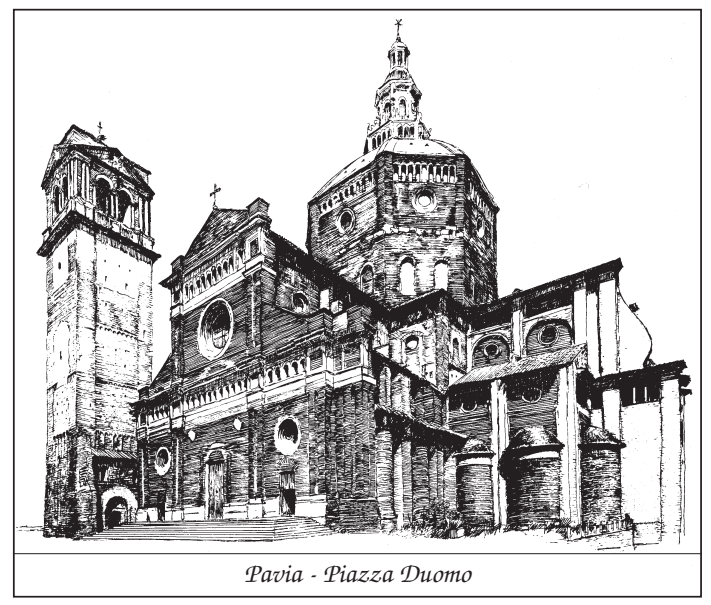

